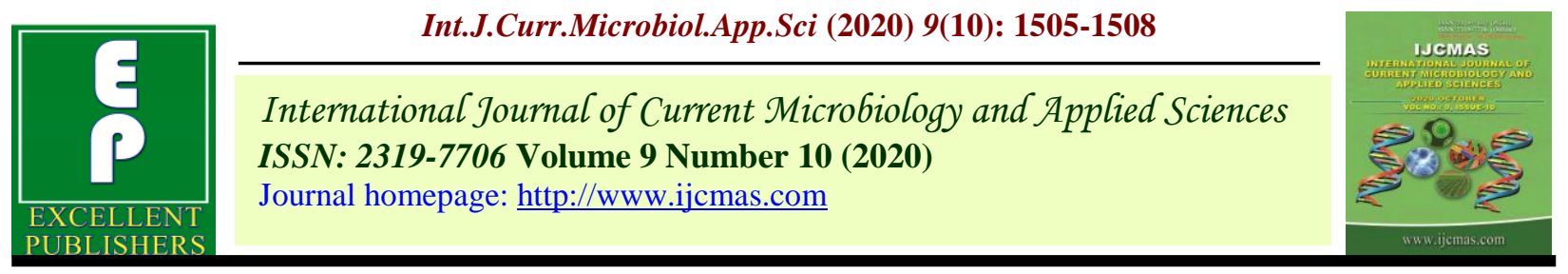

Original Research Article

https://doi.org/10.20546/ijcmas.2020.910.179

\title{
Identification of Resistant Genotype of Barnyard Millet of National Screening Nursery (NSN) against Banded Blight Disease caused by Rhizoctonia solani Kuhn
}

\author{
Prahlad Singh Netam ${ }^{1 *}$, Ashwani Kumar Thakur ${ }^{2}$, Prafull Kumar ${ }^{3}$ and R. S. Netam ${ }^{1}$ \\ ${ }^{1}$ Department of Plant Patholog, ${ }^{2}$ Department of Agronomy, ${ }^{3}$ Department of Genetics and \\ Plant Breeding, SG College of Agriculture and Research Station, Jagdalpur, 494001 India \\ *Corresponding author
}

\section{A B S T R A C T}

\begin{tabular}{l} 
K e y w o r d s \\
Barnyard millet, \\
Screening, \\
Banded blight, \\
Rhizoctonia solani \\
Kuhn, Resistant \\
\hline Article Info \\
\hline $\begin{array}{l}\text { Accepted: } \\
\text { 12 September } 2020 \\
\text { Available Online: } \\
\text { 10 October } 2020\end{array}$ \\
\hline
\end{tabular}

The field experiment was conducted during Kharif 2019 at SG College of Agriculture and Research Station, Jagdalpur, IGKV, Raipur (CG), to identify the resistant genotypes for banded blight (Rhizoctonia solani). Result revealed that none of the genotype was found free from banded blight disease. Banded blight per cent disease index observed between 12.22 to $34.44 \%$. Genotypes VL-29 (18.15\%), VL $181(12.22 \%)$ and VL $264(19.63 \%)$ were found highly resistant against banded blight. Whereas, genotypes VL 263 (20.37\%), LRB-2 (29.20\%), LRB -10 (25.93\%), LRB-13 (25.19\%), LRB-14 (25.19\%), LRB-15 (28.52\%) and LRB -17 (24.44\%) were found resistant for banded blight. However, genotypes LRB-17 (34.44\%) and LDR-1 (Local Check 30.74\%) were observed moderately susceptible for banded blight.

\section{Introduction}

Small millets are the traditional crops, agronomically more adapted to less fertile soils. The important small millets grown in India are finger millet, kodo millet, little millet, foxtail millet, barnyard millet and proso millets (Netam R.S. et al. 2014). Barnyard millet (Echinochloa frumentacaea) is one of the hardiest millet, which is called by several names viz., Japanese barnyard millet, ooda, oaalu, sawan, sanwa and sanwank (Patro et al., 2018). In India barnyard millet is the second important small millet after finger millet having production and productivity 87 thousand tones and 857 $\mathrm{kg} / \mathrm{ha}$, respectively (Padulosi et al., 2009). The pathogen is capable of causing various diseases on a variety of susceptible agriculturally important crops (Nagaraj et al. 2010). During Kharif, 2007 thirteen entries were screened against banded blight in barnyard millet. All the entries of barnyard millet showed resistant to moderately susceptible reaction (Jain and Gupta, 2010). 


\section{Materials and Methods}

Eleven genotypes with one local check (LDR1) and one resistant check (PRB 903) under national screening nursery (NSN) were tested at New Upland Research Station cum Instructional (NURI) Farm, Lamker under SG College of Agriculture and Research Station, Jagdalpur, Bastar (CG) during Kharif season 2019. These entries were sown in two rows of 3 meter length and $22.5 \mathrm{~cm} \times 10 \mathrm{~cm}$ spacing to find out resistant sources against banded blight disease of barnyard millet.

The recommended agronomic practices were adopted at the time of crop growth period. Infected plants were examined for lesion development and disease severity was assessed on the basis of lesion length by using 0 to 5 scale (Anonymous, 1996) and presented in Table 1. Per cent Disease index (PDI) was calculated by using the following formula:

$$
P D I=\frac{\text { Sum of all disease rating }}{\text { Total no. of rating } \mathrm{xMaximum} \mathrm{disease} \mathrm{grade}} \times 100
$$

\section{Results and Discussion}

Eleven barnyard genotypes were tested for banded blight during Kharif 2019 with one local check (LDR 1) and one resistant check (PRB 903). None of the genotypes were found tolerance for banded blight.

The Per cent disease index was recorded between 12.22 to $34.44 \%$. Genotypes, VL-29 (18.15\%), VL 181 (12.22\%), VL 264 (19.63\%) were found highly resistant for banded blight. Whereas, genotypes VL 263 (20.37\%), LRB-2 (29.20\%), LRB -10 (25.93\%), LRB-13 (25.19\%), LRB-14 (25.19\%), LRB-15 (28.52\%) and LRB -17 (24.44\%) were found resistant for banded blight. However, genotype LDR-1 (Local Check 30.74\%) and LRB-17 (34.44\%) observed moderately resistant for banded blight.

Patro et al., (2017) evaluated ten varieties where the disease intensity ranges from 85.33\% (VL 207) to 97.33\% (DHBM 18-6, VL 249 and DHBM 99-6) while it was $98.67 \%$ in the local check. Divya et al., (2016) evaluated thirteen varieties the percentage disease intensity ranged from 27.9\% (ACM 10-082) to 92.5\% (RBM7-2) whereas it was $93.7 \%$ in susceptible check. Patro et al. (2014) and Nagraja et al., (2016) reported that all the small millet crops were found infected with $R$. solani. Whereas in the screening of little millet LAVT 19 and LAVT 14 were found as resistant genotypes (Table 2).

Table.1 Standard Evaluation System (SES) scale for banded blight disease

\begin{tabular}{|c|l|l|}
\hline Score & \multicolumn{1}{|c|}{ Description } & \multicolumn{1}{|c|}{ Reaction } \\
\hline $\mathbf{0}$ & No incidence & Immune \\
\hline $\mathbf{1}$ & Vertical spread of the lesions up to $20 \%$ of plant height & HR \\
\hline $\mathbf{2}$ & Vertical spread of the lesions up to $21-30 \%$ of plant height & R \\
\hline $\mathbf{3}$ & Vertical spread of the lesions up to $30-45 \%$ of plant height & MR/MS \\
\hline $\mathbf{4}$ & Vertical spread of the lesions up to $46-65 \%$ of plant height & S \\
\hline $\mathbf{5}$ & Vertical spread of the lesions up to 66-100\% of plant height & HS \\
\hline
\end{tabular}


Table.2 Reaction of barnyard millet genotype in national screening nursery (NSN) against Banded blight

\begin{tabular}{|c|l|c|}
\hline S.No. & Genotypes & Jagdalpur (PDI) \\
\hline $\mathbf{1}$ & VL-29 & $18.15 \%$ \\
\hline $\mathbf{2}$ & VL-181 & $12.22 \%$ \\
\hline $\mathbf{3}$ & VL-263 & $20.37 \%$ \\
\hline $\mathbf{4}$ & VL-264 & $19.63 \%$ \\
\hline $\mathbf{5}$ & LRB-2 & $29.26 \%$ \\
\hline $\mathbf{6}$ & LRB-10 & $25.93 \%$ \\
\hline $\mathbf{7}$ & LRB-13 & $25.19 \%$ \\
\hline $\mathbf{8}$ & LRB-14 & $25.19 \%$ \\
\hline $\mathbf{9}$ & LRB-15 & $28.52 \%$ \\
\hline $\mathbf{1 0}$ & LRB-16 & $24.44 \%$ \\
\hline $\mathbf{1 1}$ & LRB-17 & $34.44 \%$ \\
\hline $\mathbf{1 2}$ & PRB 903 (Res) & $8.52 \%$ \\
\hline $\mathbf{1 3}$ & LDR 1(Sus) & $30.7 \%$ \\
\hline & SEm \pm & 2.68 \\
\hline & C.D. $(5 \%)$ & 7.88 \\
\hline
\end{tabular}

In conclusion during the screening of eleven genotypes of barnyard millet in national screening nursery (NSN) with one resistant and one susceptible check. None of the genotype found to be immune against banded blight. Genotypes VL-29, VL 181 and VL 264 were found highly resistant for banded blight. VL 263, LRB-2, LRB -10, LRB-13, LRB-14, LRB-15 and LRB -17 was promising for banded blight resistant during the one year experimentation.

\section{Acknowledgement}

Authors acknowledge to Project Coordinator, All India Coordinated Research Project on Small Millets (ICAR), GKVK, campus, Bangalore to provide grant for experiment.

The authors also thanks to Dean S G College of Agriculture and Research Station, Jagdalpur, IGKV, Raipur, Chhattisgarh for provide all necessary facilities during experimentation.

\section{References}

Anonymous, 1996. Standard evaluation system for rice. International Rice testing programme. International Rice Research Institute Report, Philippines, 1996.

Divya, M., Patro, TSSK. and Ashok, S.2016. Evaluation of resistant source of barnyard millet varieties against banded blight (BB) disease incited by Rhizoctonia solani Khun. Frontiers on Crop Improvement, 4(2): 99-100.

Jain, A.k. and Gupta, A. K. 2010. Occurrences of banded lea and sheath blight of foxtail and barnyard millets in Madhya Pradesh. Annl.Pl.Prot.Sci., 18(1): 268-270.

Nagaraj, B.T., Gururaj Sunkad, Pramesh, D., Naik, M.K. and Patil, M.B.2017. Host Range Studies of rice Sheath Blight Fungus Rhizoctonia solani (kuhn). Int. J. Curr. Microbiol. App. Sci., 6(11): 3856-3864.

Nagraja, A., Bijendra Kumar, Jain, A.K., 
Patro, TSSK, and Nageswar Rao, TG.2016. Disease of Small Millets. Diseases of field crops and their management. Indian Phytopathological Society. New Delhi, 295-371.

Padulosi, S., Mal, B., Bala Ravi, S., Gowda, J., Gowda, KTK., Shanthakumar, G., Yenagi, N. and Dutta, M. 2009. Food Security and Climate Change: Role of Plant Genetic Resources of Minor Millets. Indian J. Plant Genet. Resour., 22(1): 1-16.

Patro, TSSK., Divya, M., Sandhyarani, Y., Triveni, U. and Anuradha, N. 2017. Identification of resistant sources against Rhizoctonia solani Khun, the incitent of sheath blight of Echinocloa frumantacea. Progressive research -An International Journal, 12(1): 125-126.

Patro, TSSK, Meena, A., Divya, M. and Anuradha, N. 2018. Identification of resistant source in donor screening nursery (DSN) of barnyard millet against Rhizoctonia solani, the cause of sheath blight. Int. J. Che. Stud., 6(4): 2514-2516.

Patro, TSSK., Neerja, B., Rani, S.Y., Keerthi, S. and Jyothsna S. 2014. Banded blightAn emerging malady in small millets. National conference on emerging challenges and opportunities in biotic and a biotic stress management. Society for scientific development in agriculture and technology, Meerut, India, p. 120.

Netam, R.S., Tiwari, R.K.S, Bahadur, A.N., Singh, D.P and Patel, D.P. 2014. Effect of sowing date and meteorological factors on the development of blast disease on finger millet crop. American International Journal of Research in Formal, Applied and Natural Science, 5(1): 01-05.

\section{How to cite this article:}

Prahlad Singh Netam, Ashwani Kumar Thakur, Prafull Kumar and Netam, R. S. 2020. Identification of Resistant Genotype of Barnyard Millet of National Screening Nursery (NSN) against Banded Blight Disease caused by Rhizoctonia solani Kuhn. Int.J.Curr.Microbiol.App.Sci. 9(10): 1505-1508. doi: https://doi.org/10.20546/ijcmas.2020.910.179 